\title{
Correlations of mesospheric winds with subtle motion of the Arctic polar vortex
}

\author{
Y. Bhattacharya and A. J. Gerrard \\ Center for Solar-Terrestrial Research, New Jersey Institute of Technology, 323 Martin Luther King Jr. Boulevard, 101 Tiernan \\ Hall, Newark, NJ 07102-1982, USA
}

Received: 24 July 2009 - Published in Atmos. Chem. Phys. Discuss.: 6 August 2009

Revised: 16 December 2009 - Accepted: 27 December 2009 - Published: 19 January 2010

\begin{abstract}
This paper investigates the relationship between high latitude upper mesospheric winds and the state of the stratospheric polar vortex in the absence of major sudden stratospheric warmings. A ground based Michelson Interferometer stationed at Resolute Bay $\left(74^{\circ} 43^{\prime} \mathrm{N}, 94^{\circ} 58^{\prime} \mathrm{W}\right)$ in the Canadian High Arctic is used to measure mesopause region neutral winds using the hydroxyl $(\mathrm{OH})$ Meinel-band airglow emission (central altitude of $\sim 85 \mathrm{~km}$ ). These observed winds are compared to analysis winds in the upper stratosphere during November and December of 1995 and 1996; years characterized as cold, stable polar vortex periods. Correlation of mesopause wind speeds with those from the upper stratosphere is found to be significant for the 1996 season when the polar vortex is subtly displaced off its initial location by a strong Aleutian High. These mesopause winds are observed to lead stratospheric winds by approximately two days with increasing (decreasing) mesospheric winds predictive of decreasing (increasing) stratospheric winds. No statistically significant correlations are found for the 1995 season when there is no such displacement of the polar vortex.
\end{abstract}

\section{Introduction}

Vertical downward lower and middle atmospheric coupling - how the troposphere reacts to reasonable changes in the state of the upper and middle atmosphere - is still a subject of active investigation. Dynamical signatures in the mid-stratosphere $(\sim 30 \mathrm{~km})$ have been seen to "propagate downwards" (Baldwin and Dunkerton, 1999, 2001; Baldwin, 2000) ahead of imminent large scale changes in the strength of the stratospheric polar vortex caused mainly by planetaryRossby waves of tropospheric origin (Andrews et al., 1987)

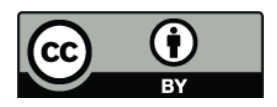

Correspondence to: Y. Bhattacharya (yajnaval@njit.edu) and by the interaction with the Aleutian High (Harvey and Hitchman, 1996). A detailed, ongoing observation and analysis of similar events is necessary to better identify the mechanisms of how the upper atmosphere can affect day-to-day weather in the troposphere. For instance, an objective of the International Polar Year 2007-2008 is to study the "Structure and Evolution of the Polar Stratosphere and Mesosphere and Links to the Troposphere during IPY" (www.ipy.org, Activity ID No: 217).

The formation of polar vortex, its gradual strengthening in winter and its breakdown in late spring superimposes a highly interactive seasonal system that is difficult to forecast with acceptable accuracy. Although the broad mechanism of transfer of dynamical information by upward propagating waves (i.e. planetary scale Rossby waves and synoptic gravity waves) and interaction of such waves with a critical layer is generally known (Andrews et al., 1987), other mechanisms such as the self-modulation of the amount of wave activity entering the stratosphere (e.g. Scott and Polvani, 2004) and wave reflection (e.g. Harnik et al., 2005) are somewhat less understood. In principle, the study of downward propagating dynamical signatures should extend from the mesospherethermospheric regions and higher down to the surface, given sufficient upper level forcing. However, continuous observations spanning weeks or months of the MLT (mesosphere, lower thermosphere) region are sparse, especially at high latitudes in the vicinity of the winter polar cap. MLT dynamics here show strong temporal and spatial variability attributed to the interacting dynamical systems - tidal, planetary and gravity waves and the polar vortex system. Detailed analysis of such observations in turn prompt advances in the understanding and predictive ability of global circulation and forecast models.

While space-based observations of the MLT region are important due to their global coverage, these observations are often prone to aliasing errors due to slow satellite precession or insufficient viewing geometry. Therefore, ground

Published by Copernicus Publications on behalf of the European Geosciences Union. 
based (i.e. localized, frequently sampled in time) observations are necessary for detailed investigation of the dynamics of signal progression between the MLT and lower atmospheric regions. Such time series analysis of wind velocities and temperatures in Arctic MLT have been recorded, amongst others, by Sivjee et al. (2003), Ozonovich et al. (1997) at Eureka, Mitchell et al. (2002) from Esrange meteor radar, Won et al. (1999) from Thule Air Base, Fisher et al. (2002), Bhattacharya et al. (2004) and Wu et al. (2005) at Resolute Bay. Walterscheid et al. (2000) have studied temperature changes using rotational temperatures from the $\mathrm{OH}$ airglow and NCEP (National Center for Environmental Prediction) assimilated data in the MLT over Eureka $\left(80^{\circ} \mathrm{N}\right)$ over a period of $\sim 35$ days during a 1993 stratospheric warming event, and compared it to the predictions of the TIMEGCM model. Rotational temperatures from $\mathrm{OH}$ airglow have also been used at the South Pole by Azeem et al. (2005), who observed signatures of the 4-day planetary wave and evidence of mesospheric cooling $\sim 15$ days preceding the increase in stratospheric temperatures.

In this paper we investigate the correlation between observed wind structure in the MLT region with assimilated daily wind speeds in the stratosphere $(3.16 \mathrm{hPa}, \sim 40 \mathrm{~km})$ during periods that are associated with both subtle polar vortex movement and the absence of stratospheric warmings. A crucial aspect of this paper is that unique data - neutral winds over from the Arctic mesopause measured almost daily over approximately 45 days, over two winters, is being analyzed at a unique time - when the polar vortex is cold and stable, without stratospheric warming events. Stable polar vortices have not been available since the mid 1990s, and the difference in the degree of distortion of the polar vortex between the two seasons has provided a valuable and rare opportunity for such analysis. Section 2 briefly describes the instrument and observations. In Sect. 3, we analyze the observations, comparing them to assimilated data from the middle atmosphere at a synoptic scale. Section 4 presents a discussion in the context of differences in the strengths of polar vortex over the two observation seasons.

\section{Data}

Wind velocities were observed using a ground-based Michelson interferometer called ERWIN (E-Region Wind Interferometer) located at Resolute Bay $\left(74^{\circ} 43^{\prime} \mathrm{N}, 94^{\circ} 58^{\prime} \mathrm{W}\right)$. ERWIN is a wide-angle interferometer, in which an ordinary Michelson is made to be independent of the angle of incident rays by inserting a glass plate in one of the arms, described in detail by Gault et al. (1996). This configuration enables scanning a single fringe by making the off-axis angle as large as possible, suitable for studying faint airglow emission. The instrument measures wind velocities in the MLT region by observing the Doppler shift of the wavelength of the linecenter of three airglow emissions. This paper presents obser- vations of the Meinel $\mathrm{OH}(6,2) \mathrm{P} 1(3)$ airglow emission linecenter at $843.0 \mathrm{~nm}$, at a nominal altitude of $\sim 85 \pm 5 \mathrm{~km}$. Measured wind velocities should be considered to be an average over this altitude range.

Observations from the ERWIN Michelson Interferometer are of high quality. Accuracy of measurements is typically $1 \mathrm{~m} / \mathrm{s}$ for a single observation, with an integration time of 1-2 s. A full set of measurements- zonal and meridional winds - takes about $20 \mathrm{~min}$ in the instrument configuration used for this paper. An excellent correlation was found in simultaneously measured wind velocities (corresponding to the $\sim 97 \mathrm{~km}$ green-line airglow emission) from ERWIN and a ground-based Fabry-Perot instrument (CLIO), also located at Resolute Bay (Fisher et al., 2000). Uninterrupted measurements are possible during darkness (polar winter) without significant cloud cover or bright moonlight within the instrument field-of-view.

For comparison and correlation with stratospheric winds, daily mean winds over Resolute Bay from UKMO Stratospheric Assimilated Data have been used. The assimilation procedure and the data are described in detail by Swinbank and O'Neil (1994). Assimilation uses the UKMO general circulation model with input data (mainly temperatures) from radiosondes and satellites. Model output for an initial 1-day run is used for the next round of input. Results are interpolated to a UARS (Upper Atmospheric Research Satellite) vertical grid, separated by a factor of $10^{\frac{1}{6}}$ in pressure levels, with a horizontal grid size of $3.75^{\circ}$ lon, $2.5^{\circ}$ lat. For this paper, the $3.16 \mathrm{hPa}(\sim 40 \mathrm{~km})$ pressure level has been used, which we feel represents the most reliable data closest to the altitude of the ERWIN wind measurements. Lower altitude wind analyses could also have been used for this study, but the associations in stratosphere-troposphere coupling have already been addressed in references cited in this paper.

Figure 1 shows the mesopause region winds $(\sim 85 \pm 5 \mathrm{~km})$ measured by ERWIN for the months of November and December, for years 1995 and 1996 over a period of $\sim 46$ days (only periods for which data is available, relatively long duration compared to typical MLT observations of wind velocities). Mean wind speeds are nominally higher for 1995 $(\sim 38 \mathrm{~m} / \mathrm{s})$ compared to $1996(\sim 33 \mathrm{~m} / \mathrm{s})$. Day-to-day variance of scalar winds is higher for $1995(208 \mathrm{~m} / \mathrm{s})$ than 1996 $(155 \mathrm{~m} / \mathrm{s})$. Average daily winds range between $13.9-88.1 \mathrm{~m} / \mathrm{s}$ for 1995 , and $16.4-76.1 \mathrm{~m} / \mathrm{s}$ for 1996 . This could be a consequence of proximity to polar vortex location which impacts wind variance in the stratosphere and very likely also in the mesosphere - the variability being higher in the vortex jet (e.g. Whiteway et al. , 1997). Observations over both seasons show dominant 12 and $24 \mathrm{~h}$ periodicity in the raw winds, followed by shorter periods (1-4h). It should be noted that traditional notion of "zonal" and "meridional" components of winds breaks down in the context of rapid polar vortex movements and distorted dynamical co-ordinates. Therefore, wind magnitudes have been considered for this analysis. It is 


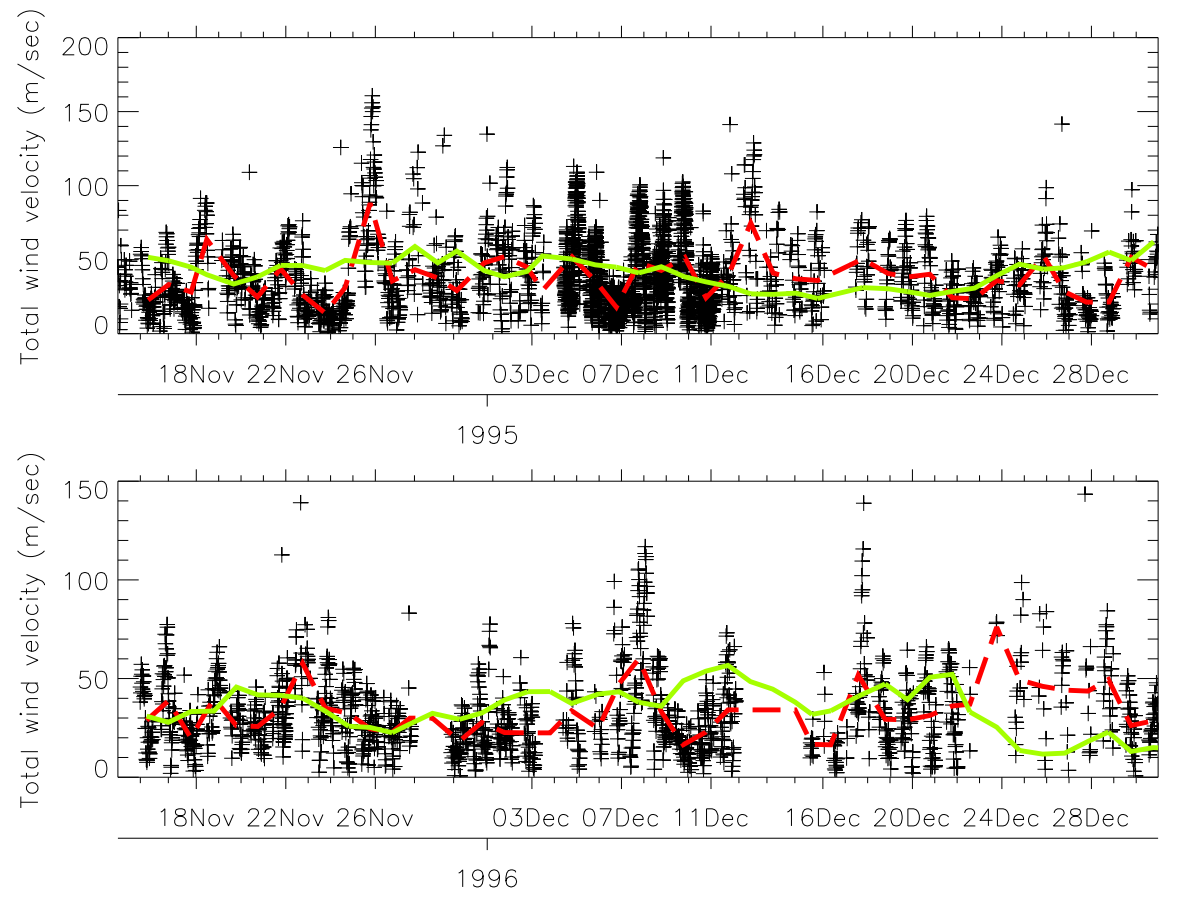

Fig. 1. Mesospheric winds as measured by ERWIN and assimilated stratospheric winds (15 November to 30 December, upper - 1995 , lower - 1996). Stratospheric winds are in green. Mesospheric winds, averaged for each day are in red. Crosses represent raw (unaveraged) ERWIN data taken in 20 min periods.

also not possible to subtract tidal amplitudes from the measured wind fields due to periodic, daily data gaps $(\sim 12 \mathrm{~h})$, and other, weather related, discontinuities in the data. Because the wind vectors are not correlated to observational windows, we assume that any tidal bias can be treated as random geophysical noise in the ERWIN data series.

\section{Analysis}

The Arctic winters of 1994/1995, 1995/1996 and 1996/1997 were characterized by relatively cold and persistent polar vortices that were not interrupted by major stratospheric warmings or vortex breakup (Pawson and Naujokat, 1999). These are ideal periods for synoptic scale case study of the stratospheric polar vortex combined with site-specific observations such as those presented herein. This is because the time series (in our case, winds) representative of stratospheric conditions can be considered "stationary" in the sense that the overall structure of the volume in and around the vortex does not significantly change over the period of observations. Gerrard et al. (2002) have shown that for synoptic studies of this nature, position and movement of the vortex must be considered when interpreting site specific observations - whether ground-based instruments, or in-situ and space-based instruments which sample the specific atmospheric region being studied infrequently temporally and spatially.
Figure 2 shows the geopotential heights (UKMO assimilated data) at five day intervals at $3.16 \mathrm{hPa}$ over the duration of observations for November-December 1995 and 1996. If the sequence of geopotential contours is taken to be a reasonable proxy for the upper stratosphere, the 1995 season is characterized by a polar vortex roughly circular in shape which extends over Resolute Bay for the entire measurement period. During the 1996 winter, the presence of a strong Aleutian high can be indirectly observed in the polar plot sequence. In the upper stratosphere, the polar vortex is progressively distorted from its circular shape and spatially displaced off of Resolute (i.e. no longer below the geographic point where the mesopause is sampled). Time series corresponding to these two different local conditions $(1995,1996)$ thus complement each other nicely in this correlation study, aided by the fact that for both the seasons, the vortex shape and relative location return to (roughly) their initial conditions.

Figure 3 shows the cross correlations of mesopause winds (observed daily average as per Fig. 1, scalar) with daily assimilated stratospheric winds over $\sim 45$ days (15 November30 December) of 1995 and 1996 as a function of daily lag. Average mesopause winds were computed with data for each day, generally available for several hours. Observations were unavailable for days 346-348 in 1996. These were substituted with the average wind speed for the entire season. 


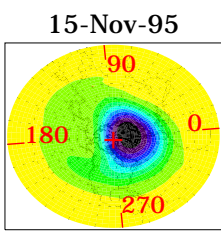

10-Dec-95

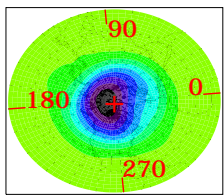

15-Nov-96

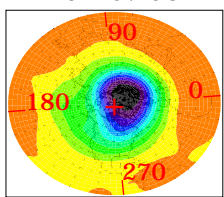

10-Dec-96
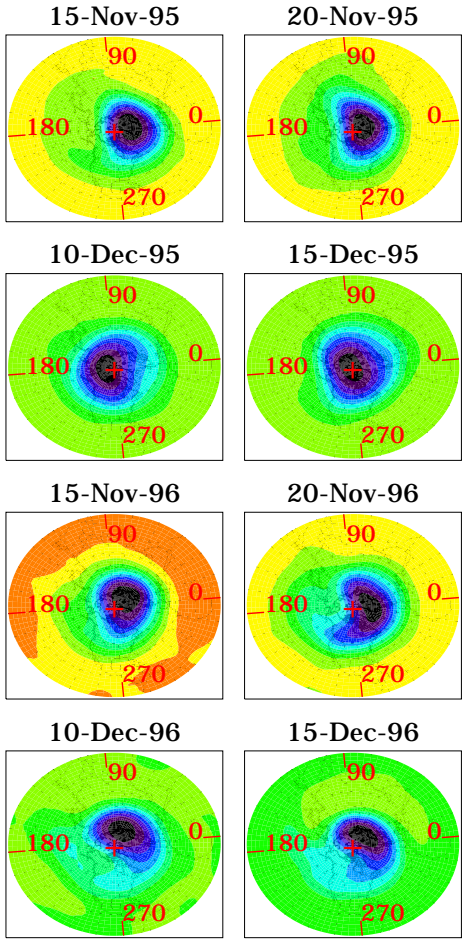

15-Dec-95

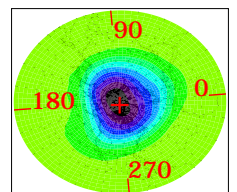

20-Nov-96

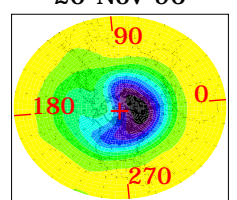

15-Dec-96
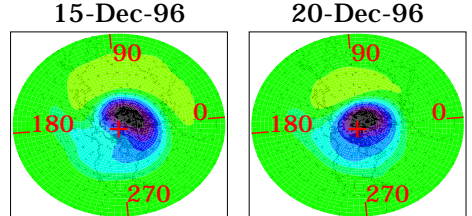

25-Nov-96
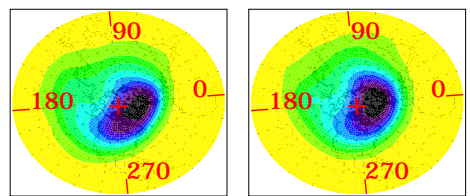

25-Dec-96
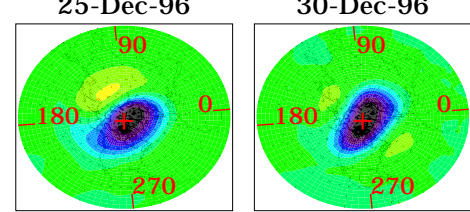

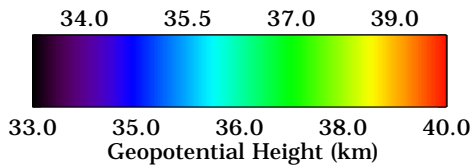

Fig. 2. Geopotential height fields for the period 15 November to 30 December, for 1995 (top two rows) and 1996 (bottom two rows) from UKMO analyses. The black cross represents the location of the ERWIN instrument at Resolute Bay.

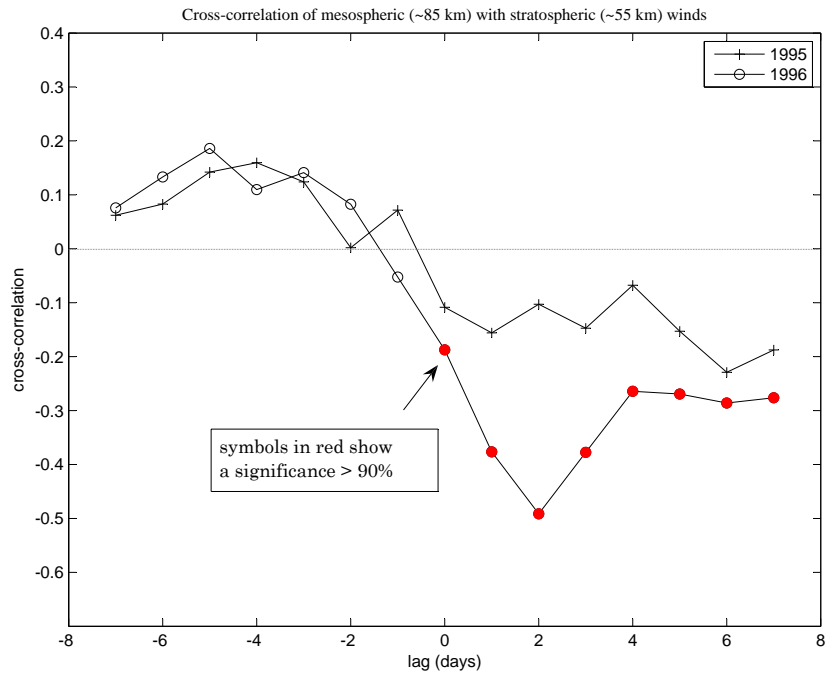

Fig. 3. Cross-correlation of upper-mesospheric $(\sim 85 \mathrm{~km})$ and stratospheric winds (assimilated data, 3.16hPa) for 1995 and 1996.

Atmos. Chem. Phys., 10, 431-436, 2010
The correlations between the mesopause winds and upper stratospheric winds for all lags in 1995 are not statistically significant and close to zero, indicating no apparent connection between the mesopause and upper stratosphere. This is expected due to the undisturbed nature of the polar vortex in 1995 and thus this "quiet polar vortex" time period acts as a control case. In contrast, for the 1996 season, a statistically significant (i.e. significance $>90 \%$ ) negative correlation of $\sim-0.5$ is found at a +2 day lag. There are also weak negative correlations for other positive lag values that are statistically significant and these correlations taper toward zero for progressively higher lag values. For completeness, in both 1995 and 1996 there is a very weak and not statistically significant positive correlation for negative lags and in 1995 a very weak and not statistically significant negative correlation for positive lags.

\section{Discussion}

The significant negative correlation between higher (lower) speed mesospheric winds and lower (higher) speed 
stratospheric winds, observed with a lag of +2 days, suggests that mesospheric winds are "leading" the stratospheric wind fields. That is, an increasing (decreasing) mesospheric wind leads a decreasing (increasing) stratospheric winds by approximately 2 days. This anti-correlation can be seen, for example, in Fig. 1 where on 7 December 1996 the mesospheric winds start to decrease and 2-days later (9 December 1996) the stratospheric winds start to increase. The opposite trend can be seen just after this period on 10 December 1996 as mesospheric winds start to increase and stratospheric winds start to decrease on 12 December 1996. This anti-correlation is only observed in the 1996 winter when the entire polar vortex is seen to be continuously subtly displaced from its nominal position away from Resolute Bay (the location of mesospheric measurements), presumably due to an interaction with the Aleutian High - as can be inferred from Fig. 2.

We suspect that the change in mesospheric winds is caused due to a top level displacement of the polar vortex by the interaction of the Aleutian High or possibly some planetary wave system. This top level displacement is transmitted downward in altitude to the upper stratosphere and observed in Fig. 2. The physical nature of this transmission mechanism is unclear and could be due to 1) phase/amplitude delay of upward propagating planetary waves or 2) via creation of a new critical layer that lowers the breaking altitude of subsequent planetary waves (Baldwin and Dunkerton, 1999, 2001; Baldwin, 2000). In any case, we suspect that the dynamical result is a displacement of the polar vortex structure in the upper stratosphere. These observations are unique from earlier papers (e.g. Walterscheid et al., 2000; Azeem et al., 2005) which also reported on high latitude, wintertime, mesospheric-stratospheric relationships in that 1) neither of the two seasons analyzed here resulted in even a minor stratospheric warming, let alone a major warming and 2) direct MLT wind measurements have been used here whereas previous studies have measured, and deduced coupling correlations from, temperature fields.

\section{Conclusions}

Our analysis suggests a possible (but not proven) downward propagating, synoptic, dynamical signatures in wind fields traced from the MLT region in the Arctic polar cap to the upper stratosphere. This should be interpreted as a possible indication of only downward signal propagation, since causal effect cannot be determined. To determine a causal effect would require further, detailed investigation of observations from similar situations - simultaneous measurements and underlying cause of mesospheric wind behaviour as well as causal relations between relative movements of a relatively undisrupted stratospheric polar vortex off the pole and movement back to "normal" - centered at the pole. Before a causal relationship can be deduced, the forcing(s) experienced by the polar vortex would have to be separated into those that can be traced in the troposphere - and the residual movements that could be attributed to alternative forcing mechanisms. The observed change in the mesospheric winds, correlated with planetary wave activity associated with the Aleutian High, appears to sequentially progress towards a displacement of the polar vortex which is later identified in stratospheric analyses.

Specifically, our observations show that, for 1996, when the cold, stable winter Arctic polar vortex is displaced horizontally away from the sampled mesopause volume due to a strong Aleutian High, decreasing (increasing) stratospheric winds lag increasing (decreasing) mesospheric winds by approximately two days. Such a correlation is absent in the wind-speed time-series during 1995 when the observed volume of the mesopause falls within the stratospheric polar vortex; typical of a very stable vortex. If confirmed by additional observations, such analyses could improve forecasting of the state of the upper stratosphere and should enable a small suite of similar observations to synoptically predict a change in stratospheric circulation on the order of days in advance.

Acknowledgements. The authors of this paper would like to thank the National Science Foundation for support through NSF-ATM0457277 and NSF-ATM-0735452. Data presented in this paper is based on ERWIN observations used in the first author's (YB) $\mathrm{Ph}$. D. thesis. We would also like to thank G. G. Shepherd, W. A. Gault and S. Brown of York University, Canada for the design and maintenance of ERWIN and use of its data. Operation and accommodation of the ERWIN instrument were supported by the Natural Sciences and Engineering Research Council of Canada and the National Science Foundation respectively.

Edited by: Franz-Josef Lübken

\section{References}

Andrews, D. G., Holton, J. R., and Leovy, C. B.: Middle Atmosphere Dynamics, Academic Press, 253-258, 1987.

Azeem, S. M. I., Talaat, E. R., Sivjee, G. G., Liu, H.-L., and Roble, R. G.: Observational study of the 4-day wave in the mesosphere preceding the sudden stratospheric warming events during 1995 and 2002, Geophys. Res. Lett., 32, L15804, doi:10.1029/2005GL023393, 2005.

Baldwin, M. P. and Dunkerton, T. J.: Downward propagation of the Arctic Oscillation from the stratosphere to the troposphere, J. Geophys. Res., 104, 30937-30946, 1999.

Baldwin, M. P.: The Arctic Oscillation and its role in stratospheretroposphere coupling, SPARC Newsletter, 14, 2000.

Baldwin, M. P. and Dunkerton, T. J.: Stratospheric harbingers of anomalous weather regimes, Science, 294, 5542, doi:10.1126/science.1063315, 2001.

Bhattacharya, Y., Shepherd, G. G., and Brown, S.: Variability of atmospheric winds and waves in the Arctic polar mesosphere during a stratospheric sudden warming, Geophys. Res. Lett., 31, 2301, doi:10.1029/2004GL020389, 2004.

Fisher, G. M., Killeen, T. L., Wu, Q., Reeves, J. M., Hays, P. B., Gault, W. A., Brown, S., and Shepherd, G. G.: Polar Cap 
Mesosphere Wind Observations: Comparisons of Simultaneous Measurements with a Fabry-Perot Interferometer and a FieldWidened Michelson Interferometer, Appl. Optics, 39, 42844291, 2000.

Fisher, G. M., Niciejewski, R. J., Killen, T. L., Gault, W. A., Shepherd, G. G., Brown, S., and Wu, Q.: Twelve-hour tides in the winter northen polar mesosphere and lower thermosphere, J. Geophys. Res., 107(A8), 1211, doi:107:SIA24-1-24-16, 2002.

Gault, W. A., Brown, S., Moise, A., Liang, D., Sellar, G., Shepherd, G. G., and Wimperis, J.: ERWIN: an E-region wind interferometer, Appl. Optics, 35, 2913-2922, 1996.

Gerrard, A. J., Kane, T. J., Thayer, J. P., Duck, T. J., Whiteway, J. A., and Fiedler, J.: Synoptic-scale study of the Arctic polar vortex's influence on the middle atmosphere: 1. Observations, J. Geophys. Res., 107(D16), 4276, doi:10.1029/2001JD000681, 2002.

Harnik, N., Scott, R. K., and Perlwitz, J.: Wave reflection and focusing prior to the major stratospheric warming of September 2002, J. Atmos. Sci., 62, 640-650, 2005.

Harvey, V. L. and Hitchman, M. H.: A Climatology of the Aleutian High, J. Atmos. Sci., 53, 2088-2102, 1996.

Manson, A. H., Meek, C., Chshyolkova, T., McLandress, C., Avery, S. K., Fritts, D. C., Hall, C. M., Hocking, W. K., Igarashi, K., MacDougall, J. W., Murayama, Y., Riggin, D. C., Thorsen, D., and Vincent, R. A.: Winter warmings, tides and planetary waves: comparisions between CMAM (with interactive chemistry) and MFR-MetO observations and data, Ann. Geophys., 24, 24932518, 2006, http://www.ann-geophys.net/24/2493/2006/.

Mitchell, N. J., Pancheva, D., Middleton, H. R., and Hagan, M. E.: Mean winds and tides in the Arctic mesosphere and lower thermosphere, J. Geophys. Res., 107(A1), 1004, doi:10.1029/2001JA900127, 2002.
Ozonovich, I., McEwen, D. J., Sivjee, G. G., and Walterscheid, R.L.: Tidal oscillations of the Arctic upper mesosphere and lower thermosphere in winter, J. Geophys. Res., 102(A3), 4511-4520, 1997.

Pawson, S. and Naujokat, B.: The cold winters of the middle 1990s in the northern lower stratosphere, J. Geophys. Res., 104, 14209$14222,1999$.

Scott, R. and Polvani, L.: Stratospheric control of upward wave flux near the tropopause, Geophys. Res. Lett., 31, L02115, doi:10.1029/2003GL017965, 2004.

Sivjee, G., McEwen, D., and Walterscheid, R.: Polar Cap Disturbances: Mesosphere and Thermosphere \pm Ionosphere Response to Solar-Terrestrial Interactions, Sodankyl $\ddot{a}$ Geophysical Observatory Publications, 122, 686-702, 2003.

Swinbank, R. S. and O'Neill, A.: A stratosphere-troposphere data assimilation system, Mon. Weather Rev., 122, 686-702, 1994.

Walterscheid, R. L., Sivjee, G. G., and Roble, R. G.: Mesospheric and Lower Thermospheric Manifestations of a Stratospheric Warming Event over Eureka, Canada (80 N), Geophys. Res. Lett., 27, 2897-2900, 2000.

Whiteway, J. A., Duck, T. J., Donevan, D. P., Bird, J. C., Pal, S. R., and Carswell, A. I.: Measurements of gravity wave activity within and around the Arctic stratospheric vortex, Geophys. Res Lett., 24, 1387-1390, 1997.

Won, Y.-I., Niciejewski, R. J., Killeen, T. L., Johnson, R. M., and Lee, B. Y.: Observations of high-latitude lower thermospheric winds from Thule Air Base and Sondre Stromfjord, Greenland, J. Geophys. Res., 104, 25-32, 1999.

Wu, Q., Gablehouse, R. D., Killeen, T. L., and Solomon, S. C.: Multi-year high latitude mesospheric neutral wind observations using a Fabry Perot interferometer, Adv. Space Res., 35(11), doi:10.1016/j.asr.2005.05.112, 2005. 